\title{
ANALISIS FAKTOR - FAKTOR YANG MEMPENGARUHI LAMA WAKTU TUNGGU (DWELLING TIME) BONGKAR MUAT DI PELABUHAN TANJUNG EMAS SEMARANG
}

\author{
Dedy Rusmiyanto ${ }^{{ }^{*}}$, I Ketut Alit Sumardiatna ${ }^{2}$ \\ ${ }^{1}$ Program studi Teknik Transportasi laut, Fakultas Teknik,Universitas Maritim AMNI \\ Jl.Sukarno - Hatta 180, Semarang \\ ${ }^{2}$ Program studi Transportasi, Fakultas Ekonomi dan Bisnis,Universitas Maritim AMNI \\ Jl.Sukarno - Hatta 180, Semarang \\ *Email :dedy.mtsundip@gmail.com
}

\begin{abstract}
Abstrak
Pelabuhan Tanjung Emas Semarang pada saat ini menjadi pilihan masyarakat khususnya di Jawa Tengah dalam menggunakan jasa transportasi laut, karena selain mengangkut dalam jumlah yang besar juga menempuh jarak yang jauh. Arus container yang melalui Pelabuhan Tanjung Emas Semarang semakin meningkat. Hal ini dapat dilihat dari pertumbuhan bongkar muat peti kemas (container) dari tahun ke tahun. Untuk mengantisipasi lonjakan permintaan pengiriman barang melalui Pelabuhan Tanjung Emas Semarang, maka sarana dan prasarana di pelabuhan harus diperhatikan karena hal tersebut akan berpengaruh langsung kepada kinerja pelabuhan. Tujuan penelitian ini untuk menganalisis pengaruh antara variable independen terhadap variable dependen, dengan populasi pegawai TKBM (Tenaga Kerja Bongkar Muat) PT. Pelabuhan Indonesia III Tanjung Emas Semarang dan diambil sampel sebanyak 80 responden. Dari hasil penelitian terdapat hubungan antara variabel bebas dengan variabel terikat, Pengujian hipotesis menggunakan uji t menunjukkan bahwa ketiga variabel bebas yaitu Faktor bongkar muat (X1), faktor penjaluran barang (X2), faktor kondisi alam (X3) yang diteliti terbukti variabel (X1 dan X2) berpengaruh positif dan signifikan mempengaruhi variabel terikat yaitu Dwelling time (Y), sedangkan variabel (X3) tidak berpengaruh positif dan signifikan terhadap Dwelling time $(Y)$ dan variable faktor bongkar muat (X1) memiliki pengaruh tertinggi yaitu $(6,227)$ daripada variabel yang lain dalam mempengaruhi faktor keputusan perusahaan pelayaran. Pada uji koefisien determinasi ( $R$ Square) nilai Adjust $R$ square sebesar 0,346 artinya $34,6 \%$ variasi variabel terikat Dwelling time dapat dijelaskan oleh variabel bebas bongkar muat, penjaluran barang dan kondisi alam. Sedangkan sisanya yaitu 65,4\% dijelaskan oleh sebab-sebab yang lain diluar variabel yang diteliti.
\end{abstract}

Kata kunci : Bongkar Muat, Penjaluran Barang dan Kondisi Alam

\section{PENDAHULUAN}

Salah satu sarana transportasi yang sangat murah untuk menunjang kegiatan ekspor-impor adalah transportasi melalui laut. Transportasi melalui laut memegang peranan yang sangat penting bagi transportasi nasional maupun pertumbuhan ekonomi nasional yang secara otomatis akan dapat meningkatkan perolehan devisa negara. Pelabuhan menjadi simpul penting untuk membangun teritorial maritim yang kuat. Pelabuhan sebagai penyedia jasa kepelabuhanan diharapkan mampu memberikan pelayanan yang prima, sehingga eksportir maupun importir tidak dirugikan dengan peningkatan biaya akibat pelayanan yang tidak optimal.
Saat ini jumlah pelabuhan di Indonesia sebanyak 2060 buah, terdiri dari pelabuhan khusus dan umum. Pelabuhan Tanjung Emas Semarang yang berada di bawah manajemen PT. Pelabuhan Indonesia III (Persero), merupakan pelabuhan yang penting dan strategis bagi sistem transportasi laut maupun perkembangan perekonomian Pulau Jawa khususnya dan Indonesia pada umumnya. Tantangan dan ancaman yang dihadapinya sangat besar mengingat persaingan antar Pelabuhan Indonesia di Indonesia maupun persaingan antar pelabuhan-pelabuhan luar negeri yang dewasa ini meningkat. Dwelling time atau waktu tunggu kadang disebut waktu tinggal bongkar muat Peti Kemas di Pelabuhan merupakan masalah klasik yang belum dapat 
diselesaikan di Indonesia. Lamanya masalah klasik yang belum dapat dwelling time cukup merugikan perekonomian, utamanya harga barang pada konsumen menjadi mahal karena harus menanggung biaya efisiensi akibat $d$ welling time peraturan terutama yang berhubungan dengan penimbunan barang dan kelancaran arus barang. (Ricadianto dkk, 2018).

Pelabuhan Tanjung Emas Semarang memiliki potensi yang sangat besar untuk dikembangkan dimasa mendatang. dalam proses bongkar muat setiap satu kapal yang seharusnya memakan waktu 1 hari tetapi bisa memakan waktu sampai 1 hari lebih dan bisa juga sampai memakan waktu 2 hari lebih bisa saja dikarenakan kurangnya akses jalur barang, kesalahan dokumen barang, dan faktor alam dan kinerja operasional dari petugas yang ada kurang baik dalam mengatur kinerja. Lamanya surat izin bongkar muat sangat berpengaruh pada waktu bongkar muat, karena faktor keadaan kapal kurang sehat sehingga dokumen bongkar muat tidak di keluarkan dan lain sebagainya, semua itu akan mengakibatkan adanya waktu tunggu (dwelling time) bongkar muat maka dari itu harus ada cara untuk memotong alur yang mengakibatkan terjadinya dwelling time, karena semua itu akan merugikan semua pengguna jasa yang memakai jasa lewat laut (Prasadja Ricardinto dkk, 2018)

Dari studi pendahuluan yang dilakukan adanya indikasi terjadinya dwelling time di Pelabuhan Tanjung Emas Semarang. Apabila kinerja pelabuhan tidak optimal maka akan berdampak langsung terhadap pelayanan di lapangan sehingga akan menimbulkan permasalahan baru yaitu waktu tunggu bongkar muat (dwelling time) semakin tinggi, sehingga akan menimbulkan ekonomi biaya tinggi, yang berdampak langsung dengan harga barang di pasaran.

\section{LANDASAN TEORI \\ Waktu Tunggu Bongkar Muat (Dwelling time)}

Dwelling time atau waktu tunggu kadang disebut waktu tinggal bongkar muat Peti Kemas di Pelabuhan merupakan diselesaikan di Indonesia. Sebenarnya, dwelling time masalah yang sederhana dan merupakan bagian kecil dari manajemen pelabuhan. Hal-hal penting yang harus dilakukan dalam menyelesaikan dwelling time, mengelola pelabuhan dengan baik, memotong jalur birokrasi yang rumit, dan menggunakan satu sistem yang disinkronkan untuk semua layanan (Rafi dan Purwanto, 2016). Dwelling time merupakan rentan waktu yang dibutuhkan peti kemas sejak dilakukan bongkar muat di kapal hingga keluar dari pelabuhan setelah menyelesaikan proses dokumen. Lamanya dwelling time cukup merugikan perekonomian, utamanya harga barang pada konsumen menjadi mahal karena harus menanggung biaya efisiensi akibat $d w e l l i n g$ time (Maulana dan Januarita, 2016).

Dwelling time adalah waktu yang dihitung mulai dari satu peti kemas (kontainer) dibongkar dan diangkat dari kapal hingga peti kemas tersebut meninggalkan terminal pelabuhan melalui pintu utama (Panggabean, dkk 2016). Dwelling time menghabiskan waktu hingga satu bulan, ada juga yang memakan waktu sangat singkat, lama juga karena menunggu dokumen.

\section{Kegiatan Bongkar Muat di Pelabuhan}

Menurut B.S. Herman Kegiatan bongkar muat adalah kegiatan membongkar barangbarang dari atas kapal dengan menggunakan crane dan sling kapal ke daratan terdekat di tepi kapal, yang lazim disebut dermaga, kemudian dari dermaga dengan menggunakan lori, forklift, atau kereta dorong, dimasukkan dan ditata ke dalam gudang terdekat yang ditunjuk oleh syahbandar pelabuhan. Sementara kegiatan muat adalah kegiatan yang sebaliknya (Basuki dkk, 2015). Operasi bongkar muat dari dan ke kapal ada 4 macam, yaitu:

1. Kegiatan Stevedoring

Proses diturunkannya barang - barang muatan dari dek kapal menuju ke pinggir pelabuhan dengan menggunakan alatalat berat bongkar muat. 
2. Kegiatan Cargodoring

Proses dibawahnya barang - barang muatan kapal yang sudah ada di pinggir pelabuhan menuju kegudang penyimpanan.

3. Kegiatan Deliverydoring

Proses pengiriman barang - barang muatan kapal dari gudang ke tempat penyimpanan.

4. Kegiatan receivedoring

Proses pengangkutan kembali barang yang ada di pabrik atau perusahaan atau industri untuk dikirim kembali ke gudang penyimpanan pelabuhan.

\section{Penjaluran Barang}

Sesuai dengan tugas DJBC (Direktorat Jendral Bea dan Cukai) harus melakukan pemeriksaan barang secara selektif dengan metode sistem penjaluran pengeluaran barang impor. Prosedur penetapan jalur pengeluaran barang impor dalam rangka pemeriksaan barang secara selektif diterapkan DJBC (Direktorat Jendral Bea dan Cukai) ada empat jalur. Keempat jalur tersbut yaitu: Jalur merah, Jalur Kuning, Jalur Hijau, Jalur MITA (Mitra Utama). Jalur merah ditetapkan berdasarkan beberapa kriteria di antaranya, importir baru, importir/barang impor termasuk kategori berisiko tinggi, barang impor sementara, barang re-impor, terkena pemeriksaan acak, dan barang impor tertentu yang ditetapkan pemerintah. Kedua, jalur kuning merupakan mekanisme pelayanan dan pengawasan pengeluaran barang impor dengan tidak dilakukan pemeriksaan fisik. Namun, barang impor tersebut tetap dilakukan penelitian dokumen sebelum penerbitan SPPB. Jalur kuning juga dapat ditetapkan jika terdapat kekurangan dalam dokumen pemberitahuan pabean beserta dokumen pelengkapnya, serta terdapat persyaratan administrasi lain yang masih kurang dan harus dilengkapi oleh importir. Ketiga, jalur hijau merupakan mekanisme pelayanan dan pengawasan pengeluaran barang impor dengan tidak dilakukan pemeriksaan fisik. Kendati demikian tetap akan dilakukan penelitian dokumen setelah penerbitan SPPB. Jalur hijau ditetapkan dalam hal importir berisiko menengah mengimpor barang berisiko rendah, importir berisiko rendah mengimpor barang berisiko rendah atau menengah. Jalur hijau juga dapat ditetapkan jika importir atau barang yang diimpor tidak termasuk dalam kriteria jalur kuning dan merah. Keempat, jalur MIta atau jalur prioritas. Jalur ini diperuntukkan bagi mitra utama (Mita), yaitu importir yang diseleksi dan ditetapkan Direktur Teknis Kepabeanan atas nama Dirjen Bea dan Cukai. Jalur Mita ini diklasifikasikan kembali menjadi dua jenis, yaitu jalur Mita prioritas dan nonprioritas.Jalur MIta prioritas dan nonprioritas sama-sama merupakan mekanisme pelayanan dan pengawasan pengeluaran barang impor dengan langsung diterbitkan SPBB tanpa dilakukan pemeriksaan fisik dan penelitian dokumen. Importir yang mendapatkan jalur ini ditetapkan pemerintah.

\section{Faktor Kondisi Alam}

Menurut Harmaini Wibowo (2010). Penyebab buruknya kenerja di pelabuhan ada hal lain yang turut mempersulit kenerja pelabuhan adalah masalah keadaan alam yang yang kurang bersahabat misalnya terjadi hujan deras disertai badai, sehingga kapal tidak bias merapat di dermaga untuk melakukan kegiatan bongkar muat, begitu juga sebaliknya operator lebuh sedikit lebih terganggu dalam melakukan aktivitasnya

\section{METODE}

1. Jenis dan Sumber Data

Jenis dan sumber data yang digunakan dalam penelitian ini adalah data primer, yaitu data yang diperoleh langsung di lapangan baik melalui wawancara dengan pihak terkait, kuesioner, dan observasi langsung, serta data sekunder, yaitu data yang telah diolah dan diperoleh dari perusahaan maupun pihak-pihak terkait. 
2. Metode Pengumpulan Data

Data yang dikumpulkan dalam penelitian ini, dilakukan menggunakan teknik :

a. Wawancara bebas yaitu teknik untuk memperoleh informasi dan melengkapi data dengan mewawancarai pihak-pihak terkait, baik itu pihak pemerintah, swasta, dan masyarakat.

b. Observasi yaitu teknik yang digunakan untuk melengkapi data dengan melihat dan mencermati secara langsung ke obyek yang akan diteliti.

c. Metode dokumentasi yaitu teknik dengan menelaah dokumen dokumen dan laporan - laporan yaitu data sekunder yang berhubungan dengan tujuan penelitian.

d. Kuesioner merupakan teknik mengumpulkan data dengan memberikan beberapa pertanyaan kepada setiap responden berdasarkan data-data yang dibutuhkan dalam penelitian.

\section{Populasi dan Sampel}

Populasi dari penelitian ini adalah 342 TKBM (Tenaga kerja bongkar muat PT. Pelabuhan Indonesi III (Persero) Cabang Semarang. Dalam penelitian ini teknik penentuan sampel yang dipakai yaitu insidential sampling. Teknik insidential sampling adalah teknik penentuan sampel berdasarkan kebetulan yaitu siapa saja yang secara kebetulan bertemu dengan peneliti dapat digunakan sebagai sampel, yang berjumlah 80 orang di PT. Pelabuhan Indonesia III (Persero) Tanjung Emas Semarang.

\section{HASIL DAN PEMBAHASAN}

\section{Uji Validitas}

Uji validitas digunakan untuk mengukur sah atau valid tidaknya suatu kuesioner. Suatu kuesioner dikatakan valid jika pertanyaan pada kuesioner mampu untuk mengungkapkan sesuatu yang akan diukur oleh kuesioner tersebut (Imam Ghozali, 2016). Untuk mengetahui indikator dikatakan valid atau tidak, dapat dilakukan dengan membandingkan $r$ hitung dengan $r$ table memakai rumus Df $=\mathrm{n}-2$.

\section{Tabel 1. Uji Validitas}

\begin{tabular}{|c|c|c|c|c|c|}
\hline \multicolumn{2}{|c|}{ Variabel } & \multirow{2}{*}{$\begin{array}{c}\begin{array}{c}\mathbf{r} \\
\text { hitung }\end{array} \\
0,735\end{array}$} & \multirow{2}{*}{$\begin{array}{c}>/< \\
>\end{array}$} & \multirow{2}{*}{$\begin{array}{c}\mathbf{r} \text { Tabel } \\
0,2864\end{array}$} & \multirow{2}{*}{$\begin{array}{c}\text { Ket. } \\
\text { Valid }\end{array}$} \\
\hline Faktor & X1.1 & & & & \\
\hline bongkar & $\mathrm{X} 1.2$ & 0,819 & $>$ & 0,2864 & Valid \\
\hline$\left(\mathrm{X}_{1}\right)$ & $\mathrm{X} 1.3$ & 0,711 & $>$ & 0,2864 & Valid \\
\hline \multirow{3}{*}{$\begin{array}{l}\text { Faktor } \\
\text { resiko } \\
\left(\mathrm{X}_{2}\right)\end{array}$} & X2.1 & 0,816 & $>$ & 0,2864 & Valid \\
\hline & $\mathrm{X} 2.2$ & 0,784 & $>$ & 0,2864 & Valid \\
\hline & $\mathrm{X} 2.3$ & 0,763 & $>$ & 0,2864 & Valid \\
\hline \multirow{3}{*}{$\begin{array}{l}\text { Faktor } \\
\text { alam } \\
\left(\mathrm{X}_{3}\right)\end{array}$} & X3.1 & 0,863 & $>$ & 0,2864 & Valid \\
\hline & X3.2 & 0,843 & $>$ & 0,2864 & Valid \\
\hline & X3.3 & 0,877 & $>$ & 0,2864 & Valid \\
\hline \multirow{3}{*}{$\begin{array}{c}\text { Dwelling } \\
\text { time } \\
\text { (Y) }\end{array}$} & Y1 & 0,957 & $>$ & 0,2864 & Valid \\
\hline & Y2 & 0,961 & $>$ & 0,2864 & Valid \\
\hline & Y3 & 0,954 & $>$ & 0,2864 & Valid \\
\hline
\end{tabular}

\section{Sumber : Data Primer yang Diolah : 2020 (out put SPSS )}

Berdasarkan tabel di atas hasil uji validitas dapat diketahui bahwa semua item pertanyaan/indikator faktor bongkar muat, faktor penjaluran barang, faktor alam dan dwelling time dinyatakan valid karena dari korelasi antara hasil jawaban responden pada tiap pertanyaan dengan skor total didapat hasil yang signifikan, yaitu nilai $r$ hitung $>r$ tabel.

\section{Uji Reliabilitas}

Reliabilitas adalah alat untuk mengukur suatu kuesioner yang merupakan indikator dari variabel atau konstruk. Suatu kuesioner dikatakan reliabel atau handal jika jawaban seseorang terhadap pertanyaan adalah konsisten atau stabil dari waktu ke waktu. Pengujian reliabilitas dlakukan dengan menggunakan program IBM SPSS 22. Dalam penelitian pengujian dilakukan terhadap 80 responden. Variabel dikatakan reliabel jika memberikan nilai Cronbach Alpha > 0,6 (Imam Ghozali, 2016). 
Tabel 2. Uji Reliabilitas

\begin{tabular}{|c|c|c|c|c|}
\hline $\begin{array}{c}\text { Variab } \\
\text { el }\end{array}$ & $\begin{array}{c}\text { Cronbach } \\
\text { Alpha }\end{array}$ & $>$ \< & $\begin{array}{c}\text { Alpha } \\
\text { Standar }\end{array}$ & Ket \\
\hline $\begin{array}{c}\text { Faktor } \\
\text { bongka } \\
\text { r muat }\end{array}$ & 0,621 & $>$ & 0,6 & Reliabel \\
\hline $\begin{array}{c}\text { Faktor } \\
\text { resiko }\end{array}$ & 0,692 & $>$ & 0,6 & Reliabel \\
\hline $\begin{array}{c}\text { Faktor } \\
\text { kondisi } \\
\text { alam }\end{array}$ & 0,825 & $>$ & 0,6 & Reliabel \\
\hline $\begin{array}{c}\text { Dwelli } \\
\text { ng time }\end{array}$ & 0,953 & $>$ & 0,6 & Reliabel \\
\hline
\end{tabular}

Sumber : Data Primer yang Diolah : 2020 (out put SPSS )

Berdasarkan table uji reliabilitas di atas memperlihatkan nilai Cronbach Alpha dari semua variabel lebih besar dari 0,6, sehingga dapat disimpulkan bahwa indikator yang digunakan oleh variabel faktor bongkar muat, faktor penjaluran barang, faktor alam dan dwelling time dapat dipercaya atau handal untuk digunakan sebagai alat ukur variabel.

\section{Uji Asumsi Klasik}

Sebelum menganalisa lebih lanjut variabel yang digunakan maka akan dilakukan pengujian terlebih dahulu dengan tujuan untuk mengetahui penyimpangan asumsi dalam variabel dengan menggunakan uji asumsi klasik. Perhitungan data dilakukan dengan menggunakan IBM SPSS 22. Pengujian yang dilakukan dalam uji asumsi klasik meliputi:

\section{a. Multikolinieritas}

Bertujuan untuk menguji apakah model regresi ditemukan adanya korelasi antar varibel bebas (independen). Model regresi yang baik seharusnya tidak terjadi korelasi di antara varibel independen (Imam Ghozali, 2016).

\begin{tabular}{|c|c|c|c|}
\hline \multicolumn{2}{|c|}{ Model } & \multicolumn{2}{c|}{ Collinearity Statistics } \\
\cline { 3 - 4 } \multicolumn{1}{|c|}{1} & Tolerance & VIF \\
\hline \multirow{4}{*}{1} & (Constant) & & \\
& Faktor bongkar & .970 & 1.031 \\
& muat & .818 & 1.222 \\
& Faktor resiko & .824 & 1.214 \\
& Faktor kondisi & & \\
& alam & & \\
& alam &
\end{tabular}

\section{Sumber : Data Primer yang Diolah :} 2020 (out put SPSS )

Berdasarkan

pengujian multikolinieritas pada table diatas perhitungan nilai tolerance menunjukkan bahwa, tidak ada variabel bebas yaitu faktor bongkar muat, faktor penjaluran barang dan faktor kondisi alam yang memiliki nilai kurang dari 0,10. Dan hasil perhitungan nilai variance inflantion factor (VIF) juga menunjukkan tidak ada variabel bebas yaitu tangible, empathy dan reliability yang memiliki nilai VIF lebih dari 10. Hal ini dapat disimpulkan bahwa tidak ada multikolonieritas antar variabel bebas dalam model regresi.

\section{b. Heteroskedastisitas}

Uji heteroskedastisitas bertujuan untuk menguji apakah dalam model regresi terjadi ketidaksamaan variance dari residual suatu pengamatan kepengamatan yang lain (Imam Ghozali, 2016).

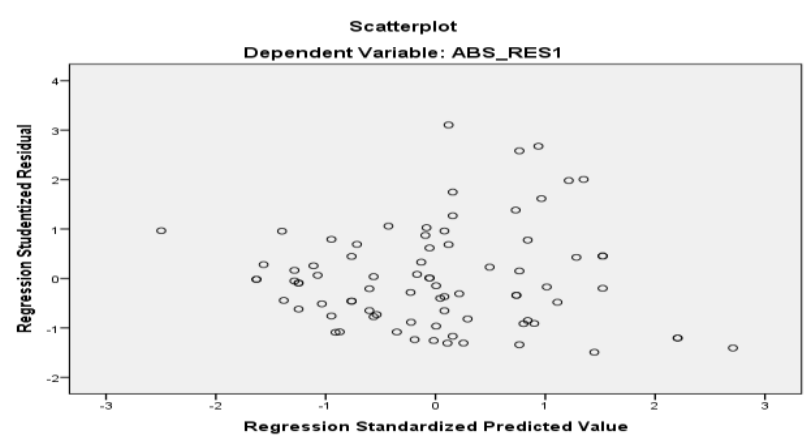

Gambar 1. Uji Heteroskedastisitas Sumber : Data Primer yang Diolah : 2020 (out put SPSS )

Berdasarkan gambar grafik scetterplots diatas bahwa titik- titik menyebar secara acak (tidak membentuk pola) serta 
tersebar baik diatas maupun dibawah angka 0 (nol) pada sumbu Y. Hali ini dapat disimpulkan bahwa tidak terjadinya heteroskedastisitas pada model regresi.

b. Uji Glejser

Uji Glejser, variabel independen signifikan secara statistik mempengaruhi variabel dependen, jika residual terdistribusi normal jika nilai Asymp.sig (2-tailed) $>0,05$. Uji glejser dapat di lihat dari hasil output berikut ini:

\section{Tabel 3. Uji Glejser}

\begin{tabular}{|c|c|c|c|c|c|c|}
\hline \multicolumn{7}{|c|}{ Coefficients $^{a}$} \\
\hline & \multirow[t]{2}{*}{ Model } & \multicolumn{2}{|c|}{$\begin{array}{l}\text { Unstandardized } \\
\text { Coefficients }\end{array}$} & $\begin{array}{l}\text { Standa } \\
\text { rdized } \\
\text { Coeffi }\end{array}$ & \multirow[t]{2}{*}{$\mathrm{T}$} & \multirow[t]{2}{*}{ Sig. } \\
\hline & & B & $\begin{array}{l}\text { Std. } \\
\text { Error }\end{array}$ & Beta & & \\
\hline \multirow{4}{*}{1} & (Constant) & 2.881 & 1.909 & & 1.509 & .389 \\
\hline & $\begin{array}{l}\text { Faktor } \\
\text { bongkar } \\
\text { muat }\end{array}$ & -101 & 105 & -111 & -960 & .340 \\
\hline & $\begin{array}{c}\text { Faktor } \\
\text { penjaluran } \\
\text { barang }\end{array}$ & -020 & .088 & -029 & -228 & .820 \\
\hline & $\begin{array}{l}\text { Faktor } \\
\text { kondisi } \\
\text { alam }\end{array}$ & .026 & .072 & .045 & .357 & .722 \\
\hline \multicolumn{7}{|c|}{ a. Dependent Variable: ABS_RES1 } \\
\hline
\end{tabular}

Sumber : Data Primer yang Diolah : 2020 (out put SPSS )

Berdasarkan pengujian heteroskedastisitas dengan menggunakan uji glatser yang terdapat pada table 4.8 bahwa nilai signifikansi variabel bebas yaitu variabel faktor bongkar muat, faktor penjaluran barang dan faktor kondisi alam lebih besar dari 0,05. Hal ini dapat disimpulkan bahwa tidak terjadinya heteroskedastisitas.

\section{Autokorelasi}

Uji Autokorelasi bertujuan untuk menguji apakah dalam model regresi linear ada korelasi antara kesalahan pengganggu pada periode $\mathrm{t}$ dengan kesalahan pengganggu periode t-1 (sebelumnya) (Ghozali,2012). Pengujian autokorelasi penelitian ini menggunakan Run Test. Jika jika pada hasil output Run test pada SPSS menunjukan Asymp.Sig (2-tailed)> nilai probabilitas 0,05 maka data terbebas dari masalah autokorelasi.

\section{Tabel 4. Autokorelasi dengan uji Run}

Test

\begin{tabular}{|l|r|}
\hline \multicolumn{2}{|c|}{ Runs Test } \\
\hline & $\begin{array}{c}\text { Unstandardized } \\
\text { Residual }\end{array}$ \\
\hline Test Value & -.05465 \\
\hline Cases $<$ Test Value & 40 \\
\hline Cases >= Test Value & 40 \\
\hline Total Cases & 80 \\
\hline Number of Runs & 35 \\
\hline Z & -1.350 \\
\hline Asymp. Sig. (2-tailed) & .177 \\
\hline
\end{tabular}

\section{Sumber : Data Primer yang Diolah :} 2020 (out put SPSS )

Hasil Output SPSS dengan Run Test menunjukan nilai Asymp. Sig. (2-tailed) sebesar 0,177 lebih dari nilai probabilitas 0,05 yang berarti dahwa model regresi terbebas dari masalah autokorelasi.

\section{Normalitas}

Uji normalitas bertujuan untuk menguji apakah dalam model regresi, variabel pengganggu atau residual memiliki disteribusi normal. (Imam Ghazali, 2016). Cara untuk melihat apakah residual terdistribusi normal atau tidak yaitu dengan dua cara yaitu analisis grafik dan uji statistik.

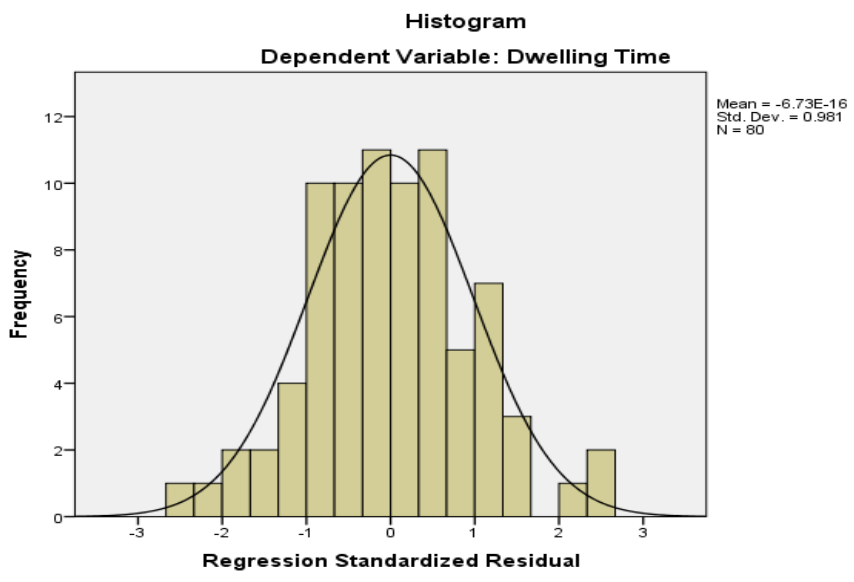

Gambar 2. Grafik Uji Normalitas Grafik Histogram

Sumber : Data Primer yang Diolah : 2020 (out put SPSS ) 
Berdasarkan pada gambar 2 diatas hasil uji normalitas grafik histogram diatas terlihat bahwa residual terdistribusi secara normal dan berbentuk simetris, tidak melenceng kekanan ataupun kekiri.

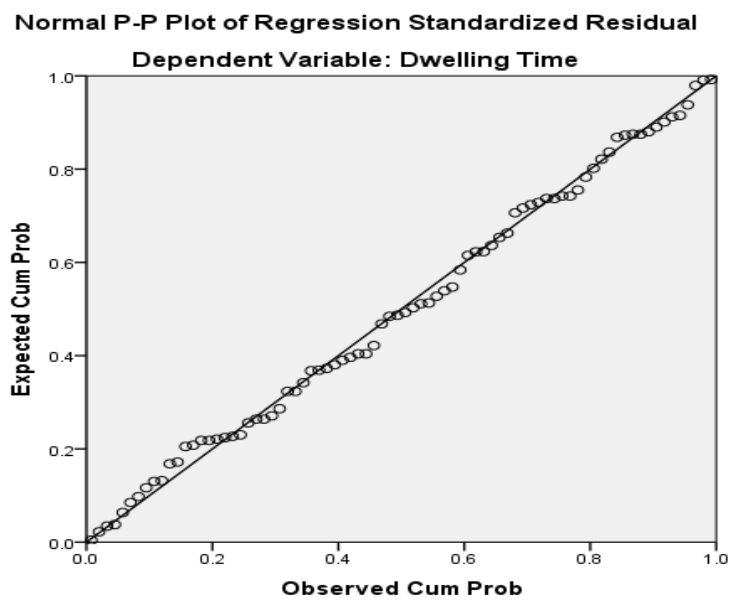

\section{Gambar 3. Uji Normalitas Normal P.P Plot}

Sumber: Data primer yang diolah : 2020 (output SPSS 22)

Pada gambar diatas hasil uji normalitas pada grafik normal P.P plot of regression standadized residual diatas terlihat titik-titik menyebar berhimpit disekitar garis diagonal dan hal ini menunjukkan bahwa residual terdistribusi secara normal.

6. Uji one sample kolmogrov smirnov digunakan untuk mengetahui distribusi data, residual terdistribusi normal jika nilai signifikansi lebih dari 0,05 .

Tabel 5. One-Sample KolmogorovSmirnov Test

\begin{tabular}{|ll|r|}
\hline & $\begin{array}{r}\text { Unstandardized } \\
\text { Residual }\end{array}$ \\
\hline $\mathrm{N}$ & Mean & 80 \\
Normal & .0000000 \\
Parameters & Std. Deviation & 2.04524931 \\
Most Extreme & Absolute & .051 \\
Differences & Positive & .048 \\
& Negative & -.051 \\
Test Statistic & & .051 \\
Asymp. Sig. (2-tailed) & $.200^{\mathrm{c}, \mathrm{d}}$ \\
\hline
\end{tabular}

a. Test distribution is Normal.

b. Calculated from data.

c. Lilliefors Significance Correction.

d. This is a lower bound of the true significance.

Sumber : Data Primer yang Diolah : 2020 (out put SPSS )
Dari output pada tabel diatas dapat diketahui bahwa nilai signifikansi Asymp. Sig. (2tailed) sebesar 0,200. Karena signifikansi lebih dari $0,05(0,200>0,05)$, maka dapat disimpulkan nilai residual terdistribusi normal.

\section{Analisis Regresi Linier Berganda}

Didalam penelitian ini menggunakan analisis regresi linear berganda untuk mengetahui seberapa besar pengaruh variabel bebas yaitu faktor bongkar muat, faktor penjaluran barang dan faktor kondisi alam, terhadap variabel terikat (dwelling time). Adapun persamaan regresi linier berganda yang digunakan dalam penelitian ini adalah sebagai berikut :

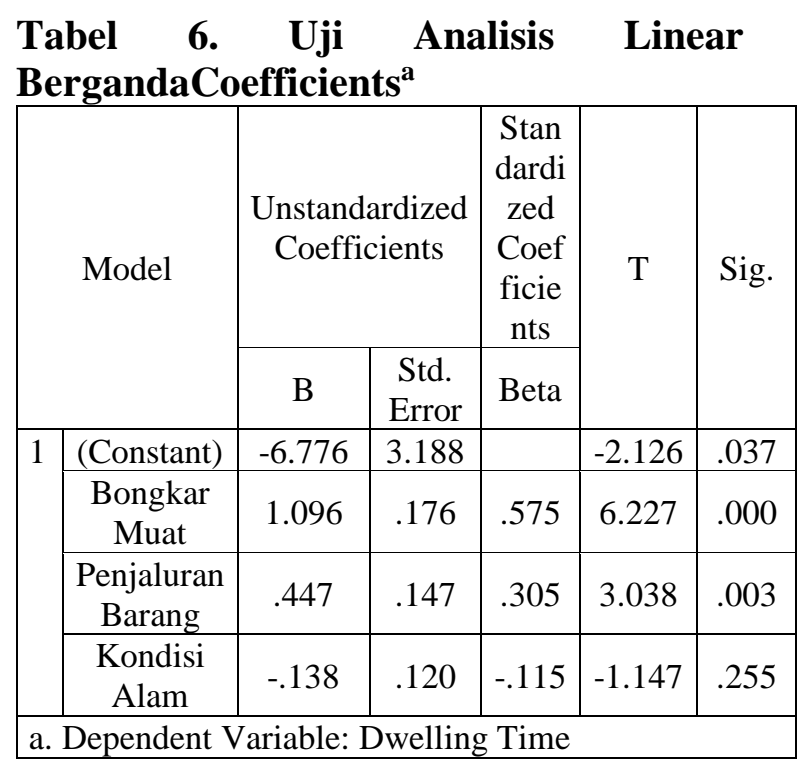

\section{Sumber : Data Primer yang Diolah :} 2020 (out put SPSS )

Dilihat dari hasil perhitungan pada tabel 6 dengan menggunakan alat bantu IBM SPSS 22 dapat diketahui bahwa persamaan regresi linear berganda adalah sebagai berikut : $Y=0,37+0,575 X 1+0,305 X 2-0.115 X 3$ $+\mu$

Persamaan regresi diatas dapat dijelaskan sebagai berikut :

a. Konstanta sebesar 0,37 menyatakan bahwa jika variable independen tidak dilakukan perubahan, maka Dwelling time bernilai tetap sebesar 0,37 . 
b. Koefisien regresi variabel (X1) faktor bongkar muat sebesar 0,575 artinya jika variabel independen lain bernilai tetap dan variabel faktor bongkar muat mengalami kenaikan 1 satuan, maka variabel dwelling time (Y) akan mengalami kenaikan. Koefisien bernilai positif artinya terjadi hubungan positif antara faktor bongkar muat dengan dwelling time, semakin naik faktor bongkar muat maka semakin meningkat dwelling time.

c. Koefisien regresi variabel (X2) faktor penjaluran barang sebesar 0,305 artinya jika variabel independen lain bernilai tetap dan variabel faktor resiko mengalami kenaikan 1 satuan maka variabel dwelling time (Y) akan mengalami kenaikan sebesar 0,305 satuan. Koefisien bernilai positif artinya terjadi hubungan positif antara faktor resiko dengan dwelling time, semakin naik faktor resiko maka semakin meningkat $d$ welling time.

d. Koefisien regresi variabel (X3) faktor kondisi alam sebesar -0.115 artinya Jika terjadi kenaikan factor kondisi alam (kondisi alam membaik), maka akan dwelling time mengalami penurunan sebesar 0.115 satuan.

\section{Uji Statistik T}

Uji statistik $\mathrm{T}$ pada dasarnya menunjukkan seberapa jauh pengaruh satu variabel independen secara individual dalam menerangkan variasi variabel dependen dengan rumus n-k-1 (Imam Ghozali, 2016).

\section{Tabel 7. Uji T Coefficients ${ }^{\mathrm{a}}$}

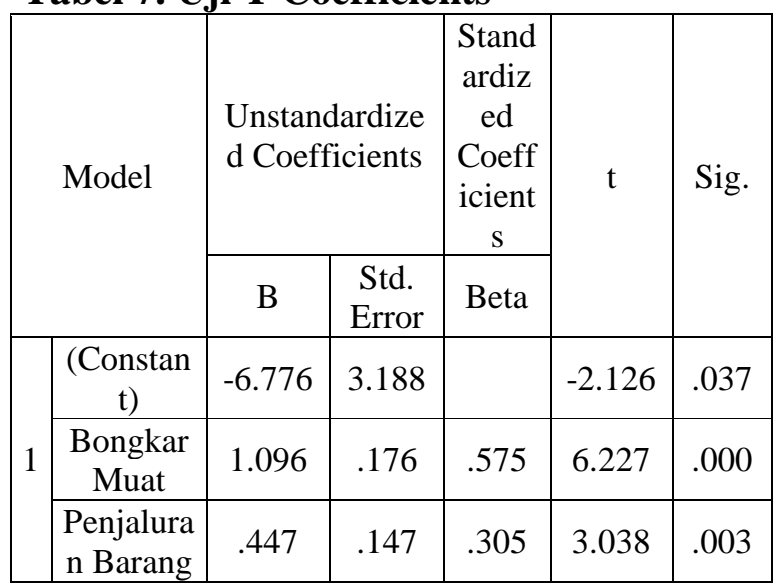

\begin{tabular}{|c|c|c|c|c|c|}
\hline $\begin{array}{c}\text { Kondisi } \\
\text { Alam }\end{array}$ & -.138 & .120 & -.115 & -1.147 & .255 \\
\hline
\end{tabular}

a. Dependent Variable: Dwelling Time

\section{Sumber: Data primer yang diolah : 2018 (output SPSS 22)}

\section{Uji Koefisien Determinasi $\left(\mathbf{R}^{2}\right)$}

Uji koefisien determinasi $\left(\mathrm{R}^{2}\right)$ digunakan untuk mengukur seberapa jauh kemampuan model dalam menerangkan variasi variable dependen. Nilai koefisien determinasi adalah antara nol sampai satu. Nilai $\mathrm{R}^{2}$ yang kecil berarti kemampuan variabel-variabel independen dalam menjelaskan variasi variabel sangat terbatas. Sedangkan nilai yang mendekati satu berarti variabel-variabel independen memberikan hampir semua informasi yang dibutuhkan untuk memprediksi variasi variabel dependen (Imam Ghozali, 2016). Berikut adalah hasil pengujian koefisien determinasi:

\section{Tabel 8. Uji Koefisien Determinasi}

\begin{tabular}{|c|c|c|c|c|c|}
\hline \multicolumn{6}{|c|}{ Model Summary ${ }^{b}$} \\
\hline $\begin{array}{c}\text { Mode } \\
1\end{array}$ & $\mathrm{R}$ & $\begin{array}{c}\mathrm{R} \\
\text { Squar } \\
\mathrm{e}\end{array}$ & $\begin{array}{c}\text { Adjuste } \\
\text { d R } \\
\text { Square }\end{array}$ & $\begin{array}{l}\text { Std. } \\
\text { Error of } \\
\text { the } \\
\text { Estimat } \\
\text { e }\end{array}$ & $\begin{array}{c}\text { Durbin } \\
- \\
\text { Watson }\end{array}$ \\
\hline 1 & $\begin{array}{c}.609 \\
\mathrm{a}\end{array}$ & .371 & .346 & 2.08523 & 1.240 \\
\hline a. $\mathrm{F}$ & & Con & 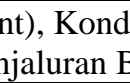 & $\begin{array}{l}\text { Alan } \\
\text { ang }\end{array}$ & ngkar \\
\hline
\end{tabular}

Sumber: Data primer yang diolah : 2020 (output SPSS 22)

Berdasarkan table diatas hasil uji koefisien determinasi di atas mengunakan bantuan program SPSS V.22 for windows didapatkan angka koefisien determinasi (Adjusted $R \quad$ Square) sebesar 0,346 $(\mathrm{R} 2=0,346 \times 100 \%)$. Hal ini berarti $34,6 \%$ variasi variabel terikat yaitu dwelling time (Y) dapat dijelaskan oleh variabel bebas yaitu faktor bongkar muat (X1), faktor penjaluran barang (X2), dan faktor kondisi alam (X3). Sedangkan sisanya $100 \%$ $34,6 \%=65,4 \%$ diduga ada variable yang lain yang belum diteliti yaitu : faktor keterlambatan pengurusan dokumen dari 
pemilik barang, kurangnya kordinasi kementrian dengan pihak pelindo, pengurusan dokumen terlalu lama, custom clereance, dan perbedaan jam kerja antara instansi dan pemilik barang, kelima variabel yang disebutkan ini adalah variabel yang tidak digunakan dalam penelitian ini.

\section{Implikasi Manajerial}

Dari pengujian yang telah dilakukan, hasil pengujian analisis dalam penelitian ini dapat digunakan sebagi sumber tambahan referensi dan informasi bagi penyusunan rencana strategis PT. Pelabuhan Indonesia (Persero) Cabang Semarang untuk dwelling time.

Hasil analisis menunjukan bahwa faktor bongkar muat dan, faktor penjaluran barang berpengaruh positif dan signifikan terhadap dwelling time. Sedangkan faktor kondisi alam berpengaruh negatif terhadap $d$ welling time. Berdasarkan hasil tersebut maka perlu adanya tindakan untuk meningkatkan dwelling time pada tingkat yang lebih tinggi. Berikut implikasi manajerialnya :

1 Dari hasil pengujian kuesioner yang telah dilakukan dan hasil regresi linier berganda menunjukkan bahwa, variable faktor bongkar muat berada pada urutan pertama diantara ketiga variabel yang mempengaruhi dwelling time, dimana indikatornya meliputi meliputi alat bongkar muat, tenaga kerja bongkar muat dan sarana transportasi. bahwa hal ini mempengaruhi dwelling time. Implikasi manajerialnya fasilitas yang memadai dapat mempengaruhi waktu pada $d$ welling time yang signifikan.

2 Dari hasil pengujian kuesioner yang telah dilakukan dan hasil regresi linier berganda menunjukkan bahwa, variabel faktor penjaluran barang berada pada urutan kedua diantara ketiga variabel yang mempengaruhi dwelling time, dimana indikatornya meliputi sumber daya manusia, organisasi dan struktur kerja dan penguasan teknologi. Implikasi manajerialnya adalah sumber daya manusia yang mumpuni yang dapat menunjang kegiatan penjaluran barang yang mempengaruhi waktu pada $d w l l i n g$ time.

3 Dari hasil pengujian kuesioner yang telah dilakukan dan hasil regresi linier berganda menunjukkan bahwa, variabel faktor kondisi alam tidak berpengaruh positif dan signifikan melainkan berpengaruh negatif terhadap variabel dwelling time, dimana indikatornya meliputi angin kencang, gelombang laut dan hujan badai, bahwa hal ini tidak mempengaruhi dwelling time. Implikasi manajerialnya adalah kondisi alam tidak berbengaruh positif yang berakibat pada lama nya waktu $d$ welling time.

Dari hasil pengujian kuesioner yang telah dilakukan dan hasil uji koefisien determinasi menunjukkan bahwa angka koefisien determinasi (Adjusted $R$ Square) sebesar $0.346 \mathrm{Hal}$ ini berarti $34,6 \%$ variabel terikat yaitu dwelling time (Y) dapat dijelaskan oleh variabel bebas yaitu faktor bongkar muat (X1), faktor penjaluran barang (X2), dan faktor kondisi alam (X3). Sedangkan sisanya $65,4 \%$ dijelaskan oleh variable yang lain yang tidak ikut diteliti.

\section{KESIMPULAN}

Berdasarkan hasil pengujian statistik dan pembahasan yang di ada pada bab sebelumnya dapat diambil beberapa kesimpulan sebagai berikut

1. Faktor bongkar muat berpengaruh positif dan signifikan dwelling time PT. Pelabuhan Indonesia III (Persero) Cabang Semarang. Hasil analisis regresi linear berganda menunjukan koefisien sebesar 0,575 , lalu pada uji t hitung menghasilkan 6,227 sedangkan nilai $\mathrm{t}$ tabel sebesar 1,991 , hasil perhitungan ini menunjukan bahwa $\mathrm{t}$ hitung $>\mathrm{t}$ tabel dengan tingkat signifikansi sebesar 0,05 . Hasil t hitung $>$ $\mathrm{t}$ tabel dan nilai signifikansi $<0,05$. Hal ini menunjukkan bahwa faktor bongkar muat yang terdiri dari fasilitas yang memadai, Jumlah personil cukup dan akses transportasi yang memadai mempengaruhi dwelling time PT. 
Pelabuhan Indonesia III (Persero) Cabang Semarang.

2. Faktor penjaluran barang berpengaruh positif dan signifikan terhadap dwelling time PT. Pelabuhan Indonesia III (Persero) Cabang Semarang. Hasil analisis regresi linear berganda menunjukan koefisien sebesar 0,305, lalu pada uji t menghasilkan $t$ hitung sebesar 3,038 sedangkan nilai $\mathrm{t}$ tabel sebesar 1,991 , hasil perhitungan ini menunjukan bahwa t hitung $>\mathrm{t}$ tabel dengan tingkat signifikansi sebesar 0,05. Hal ini menunjukan bahwa faktor penjaluran barang yang terdiri dari sumber daya manusia , organisasi dan struktur kerja dan penguasaan teknologi mempengaruhi dwelling time $\mathrm{PT}$. Pelabuhan Indonesia III (Persero) Cabang Semarang.

3. Faktor kondisi alam tidak berpengaruh positif dan signifikan terhadap dwelling time PT. Pelabuhan Indonesia III (Persero) Cabang Semarang. Hasil analisis regresi linear berganda menunjukan koefisien sebesar -0,115, lalu pada uji $\mathrm{t}$ menghasilkan $\mathrm{t}$ hitung sebesar - 1,147 sedangkan nilai t tabel sebesar 1,991, hasil perhitungan ini menunjukan bahwa $\mathrm{t}$ hitung $<\mathrm{t}$ tabel dengan tingkat signifikansi sebesar 0,05. Hal ini menunjukkan bahwa faktor kondisi alam yang terdiri dari angin kencang, gelombang laut dan hujan badai tidak mempengaruhi dwelling time PT. Pelabuhan Indonesia III (Persero) Cabang Semarang.

4. Dari hasil pengujian kuesioner yang telah dilakukan dan hasil uji koefisien determinasi menunjukkan bahwa angka koefisien determinasi (Adjusted $R$ Square) sebesar 0,346 (R2=0,346 x $100 \%$ ). Hal ini berarti $34,6 \%$ variasi variabel terikat yaitu dwelling time (Y) dapat dijelaskan oleh variabel bebas yaitu faktor bongkar muat (X1), faktor penjaluran barang (X2), dan faktor kondisi alam (X3). Sedangkan sisanya $100 \%-34.6 \%=65,4 \%$ dijelaskan oleh variable yang lain yaitu : faktor kepengurusan dokumen dari pemilik barang, kurangnya kordinasi kementrian dengan pihak pelindo, pengurusan dokumen terlalu lama, custom clereance, dan perbedaan jam kerja antara instansi dan pemilik barang, kelima variabel yang disebutkan ini adalah variabel yang tidak digunakan dalam penelitian ini.

\section{DAFTAR PUSTAKA}

Basuki, dkk, 2015, Integritas antara Dwelling Time dan Bongkar Muat Peti Kemas Pelabuhan Tanjung Priok, Jurnal Manajemen Transportasi dan Logistik, Vol.05, No.03.

Harmaini Wibowo, 2010, Jumlah Gang Kerja, Waktu, dan Cuaca Terhadap Produktivitas Bongkar Muat Kontainer

Imam Ghozali, 2016, Aplikasi Analisis Multivariate dengan Program IBM SPSS 23, Universitas Diponegoro Semarang

Maulana dan Januarita, 2018, Integritas antara Dwelling Time dan Bongkar Muat Peti Kemas Pelabuhan Tanjung Priok, Jurnal Manajemen Transportasi dan Logistik, Vol.05, No.03.

Minto Basuki,dkk 2015, Analisis Risiko Kegiatan Bongkar Muat Sebagai Komponen Dwelling Time di Pelabuhan, Institut Teknologi Adhi Tama Surabaya. ISBN 978-98569-1-0

Peraturan pemerintah nomor 64 tahun 2015 perubahan atas PP No. 61 tahun 2009. Tentang Kepelabuhanan. 